\title{
Evidence of origin with epigenetic change of metachronous lesions in early gastric cancer after endoscopic submucosal dissection
}

Yo Kubota ( $\square$ kubota@kitasato-u.ac.jp )

Kitasato University School of Medicine

Satoshi Tanabe

Kitasato University School of Medicine

Mizutomo Azuma

Kitasato University School of Medicine

Kazue Horio

Kitasato University School of Medicine

Yoshiki Fujiyama

Kitasato University School of Medicine

Takafumi Soeno

Kitasato University School of Medicine

Yasuaki Furue

Kitasato University School of Medicine

Takuya Wada

Kitasato University School of Medicine

Akinori Watanabe

Kitasato University School of Medicine

Kenji Ishido

Kitasato University School of Medicine

Chikatoshi Katada

Kitasato University School of Medicine

Keishi Yamashita

Kitasato University School of Medicine

Wasaburo Koizumi

Kitasato University School of Medicine

\section{Research Article}

Keywords: Early gastric cancer (EGC), endoscopic submucosal dissection (ESD), CD01, TAM (M) 
Posted Date: July 8th, 2021

DOl: https://doi.org/10.21203/rs.3.rs-675469/v1

License: (c) (i) This work is licensed under a Creative Commons Attribution 4.0 International License. Read Full License 


\section{Abstract}

Early gastric cancer (EGC) with metachronous lesions developing on scars after endoscopic submucosal dissection (ESD) is extremely rare and hard to treat. We evaluated whether DNA methylation of the cancer-specific methylation gene, cysteine dioxygenase type 1 (CDO1), would predict such lesions. CDO1 methylation (TaqMeth) values were compared between 11 patients with metachronous lesions developing on scars after ESD (M group) identified from 2,055 patients $(0.5 \%)$ and 33 patients with EGC with no confirmed evidence of metachronous lesions at $>3$ years after ESD (solitary [S] group). To assess Helicobacter pylori influence, 11 H. pylori-negative EGC patients ( $\mathrm{N}$ group) were also analyzed. Each ESD specimen was measured at the tumor $(T)$ and 4-points separated tumor-adjacent noncancerous mucosa (TAM). TaqMeth values for T were significantly higher than TAM $(S+M)(P=0.0019)$ and TAM $(N)(P<$ 0.0001). Moreover, TAM (M) had significantly higher TaqMeth values than TAM (S) $(P<0.0001)$ suggesting that TAM $(\mathrm{M})$ exhibited $C D O 1$ hypermethylation similar to T $(P=0.5713)$. Additionally, TaqMeth values for TAM (S) were significantly higher than TAM $(\mathrm{N})(P<0.0001)$. The receiver operating characteristic for discriminating the highest TaqMeth values separated TAMs (M) from those of TAMs (S) was 0.81 . CDO1 hypermethylation promisingly predicted EGC with metachronous lesions developing on scars after ESD.

\section{Introduction}

Gastric cancer currently ranks as the fifth most common malignant tumor and the third leading cause of mortality worldwide.[1] Consequent to Helicobacter pylori eradication, gastric cancer has decreased in recent years in Japan but remains the third leading cause of mortality among malignant tumors.[2] With the development and more common use of endoscopic submucosal dissection (ESD), ESD has become the established standard treatment for early gastric cancer (EGC).[3] With the widespread treatment of ESD for EGC, we sometimes encounter cases of EGC with metachronous lesions developing on scars after curable ESD; therefore, we strongly questioned why new EGC lesions developed on scars after curative resection for ESD. The incidence of EGC with metachronous lesions after ESD has been reported to range from $4.0-13.0 \%$.[4-6] Nonetheless, the mechanism behind the appearance of new EGC lesions on scars after curable ESD is unknown, and there have been neither clinicopathological nor molecular biological studies on EGC with metachronous lesions developing on scars after curable ESD. As a clinical problem, treating EGC that developing on scars is often technically difficult because the inflammation of the scar causes fibrosis, and the mucosal and muscular layers are adherent, which increases the risk of complications.[7] Therefore, knowledge of the molecular etiology and clinical predictors for early diagnosis and appropriate, safe treatment of EGC with metachronous lesions developing on scars is highly required.

Various genetic abnormalities such as genomic gain, genomic loss, and genomic mutations are involved in gastric cancer development.[8] Furthermore, epigenetic abnormalities, including DNA methylation, are more dominant during gastric carcinogenesis,[9] which is affected by epigenetic field cancerization in the 
tumor-adjacent noncancerous mucosa (TAM), where DNA methylation abnormalities in various genes increase as a result of chronic inflammation due to $H$. pylori infection in the gastric mucosa.[10-12]

Promoter DNA methylation, which is associated with gastric carcinogenesis, has recently attracted attention as a cancer-specific biomarker.[13] Epigenetic gene silencing of tumor suppressor genes via promoter DNA hypermethylation is a common feature among human cancers, whereas cancer-specific methylation is a relatively rare event. $[14,15]$ After demethylation treatment of cancer cell lines, we succeeded in identifying a novel methylated gene by comprehensively searching for gene expression using a microarray.[16] Additionally, we identified novel tumor suppressor gene candidates in human cancers such as cysteine dioxygenase type $1(C D 01) \cdot[14,17]$

CDO1 acts as an enzyme that converts cysteine into cysteine sulfinic acid in cells, further leading to an increase in $\mathrm{SO}_{3}{ }^{2-}$ mediated by aspartate aminotransferase (GOT1) and replenishing cystine (CYS2) in the extracellular compartment, which plays a crucial role in cancer cell stemness.[18] xCT mediates the cystine transport from the extracellular to an intracellular compartment for cancer stemness.[18] Its overexpression is accompanied by the production of nuclear factor erythroid 2-related factor 2, a central redox sensor, and results in reactive oxygen species generation, thereby promoting apoptosis.[19] Thus, $C D O 1$ has recently been considered to be a critical tumor suppressor gene involved in carcinogenesis across various human cancers. Previous reports have described the excellent cancer diagnostic performance and prognostic relevance of $C D O 1$ promoter DNA hypermethylation in various gastrointestinal cancers, including gastric cancer.[20-25] Nevertheless, there exist no reports on predictors of gastric carcinogenesis in the TAM after ESD for EGC. We believe that EGC with metachronous lesions developing on scars is a good model to provide evidence of origin with epigenetic abnormality during gastric carcinogenesis after ESD, and the current study hence aimed to confirm this association.

\section{Results}

\section{Clinicopathological characteristics}

Table 1 summarized the clinicopathological characteristics of the 55 EGC patients (S group: $n=33$; M group: $n=11$; and $\mathrm{N}$ group: $n=11$ ). The median age of all patients was 70 years (range, $31-85$ years), and the EGC patients in the $\mathrm{N}$ group were younger than those in the $S$ and $\mathrm{M}$ groups $(P=0.0004)$. There were 39 men and 16 women. With respect to $H$. pylori status at ESD treatment, 11 patients were not infected, whereas 44 patients (current infection: $n=16$; after eradication: $n=28$ ) had been infected; furthermore, all negative cases were EGC patients ( $\mathrm{N}$ group) $(P<0.0001)$. Atrophic gastric mucosa was defined according to the Kimura-Takemoto classification[26-28]; 11 patients had no atrophic gastric mucosa, all of whom were EGC patients (N group) $(P<0.0001)$, whereas 44 patients ( $\mathrm{S}$ and $\mathrm{M}$ groups) had atrophic gastric mucosa (closed type: $n=4$, open type: $n=40$ ). With respect to lesion location, 26 and 29 lesions were located in the middle and low areas, respectively, and the tumor location was different among all patients $(P<0.0001)$. As for macroscopic type, 16 lesions were flat and elevated, five lesions 
were flat, and 34 lesions were flat and depressed. As for pathological type, 39 lesions were welldifferentiated adenocarcinomas, five lesions were moderately differentiated adenocarcinomas, and 11 lesions were poorly differentiated adenocarcinomas (signet-ring cell carcinomas); histological types were different among all patients $(P<0.0001)$. Table 2 showed that no statistically significant difference in conventional clinicopathologic factors was observed between the $\mathrm{S}$ group $(n=33)$ and the M group $(n=$ 11) 
Table 1

Clinicopathological characteristics of 55 patients with EGC

\begin{tabular}{|c|c|c|c|c|c|c|}
\hline & & $\begin{array}{l}\text { EGC } \\
(n=55)\end{array}$ & $\begin{array}{l}\text { S group } \\
(n=33)\end{array}$ & $\begin{array}{l}\text { M group } \\
(n=11)\end{array}$ & $\begin{array}{l}\text { N group } \\
(n=11)\end{array}$ & $\begin{array}{l}P \\
\text { value }\end{array}$ \\
\hline Age & Median (range) & $\begin{array}{l}70 \\
(31- \\
85)\end{array}$ & $\begin{array}{l}73(58- \\
85)\end{array}$ & $\begin{array}{l}74(65- \\
84)\end{array}$ & $\begin{array}{l}58(31- \\
77)\end{array}$ & 0.0004 \\
\hline \multirow[t]{2}{*}{ Sex } & Male & $\begin{array}{l}39 \\
(70.9 \%)\end{array}$ & $\begin{array}{l}25 \\
(75.8 \%)\end{array}$ & 7 (63.6\%) & 7 (63.6\%) & \multirow[t]{2}{*}{0.6702} \\
\hline & Female & $\begin{array}{l}16 \\
(29.1 \%)\end{array}$ & $8(24.2 \%)$ & $4(36.4 \%)$ & $4(36.4 \%)$ & \\
\hline \multirow[t]{3}{*}{$\begin{array}{l}\text { H. pylori status } \\
\text { (during ESD) }\end{array}$} & Not infected & $\begin{array}{l}11 \\
(20.0 \%)\end{array}$ & $0(0.0 \%)$ & $0(0.0 \%)$ & $\begin{array}{l}11 \\
(100.0 \%)\end{array}$ & \multirow[t]{3}{*}{$<.0001$} \\
\hline & Current infection & $\begin{array}{l}16 \\
(29.1 \%)\end{array}$ & $\begin{array}{l}12 \\
(36.4 \%)\end{array}$ & $4(36.4 \%)$ & $0(0.0 \%)$ & \\
\hline & After eradication & $\begin{array}{l}28 \\
(50.9 \%)\end{array}$ & $\begin{array}{l}21 \\
(63.6 \%)\end{array}$ & 7 (63.6\%) & $0(0.0 \%)$ & \\
\hline \multirow[t]{3}{*}{ Atrophy } & No atrophy & $\begin{array}{l}11 \\
(20.0 \%)\end{array}$ & $0(0.0 \%)$ & $0(0.0 \%)$ & $\begin{array}{l}11 \\
(100.0 \%)\end{array}$ & \multirow[t]{3}{*}{$\begin{array}{l}< \\
0.0001\end{array}$} \\
\hline & Closed type & $\begin{array}{l}4 \\
(7.3 \%)\end{array}$ & $3(9.1 \%)$ & $1(9.1 \%)$ & $0(0.0 \%)$ & \\
\hline & Open type & $\begin{array}{l}40 \\
(72.7 \%)\end{array}$ & $\begin{array}{l}30 \\
(90.9 \%)\end{array}$ & $\begin{array}{l}10 \\
(90.9 \%)\end{array}$ & $0(0.0 \%)$ & \\
\hline \multirow[t]{3}{*}{ Location } & Upper & $\begin{array}{l}0 \\
(0.0 \%)\end{array}$ & $0(0.0 \%)$ & $0(0.0 \%)$ & $0(0.0 \%)$ & \multirow[t]{3}{*}{0.0003} \\
\hline & Middle & $\begin{array}{l}26 \\
(47.3 \%)\end{array}$ & $\begin{array}{l}19 \\
(57.6 \%)\end{array}$ & $7(63.6 \%)$ & $0(0.0 \%)$ & \\
\hline & Low & $\begin{array}{l}29 \\
(52.7 \%)\end{array}$ & $\begin{array}{l}14 \\
(42.4 \%)\end{array}$ & $4(36.4 \%)$ & $\begin{array}{l}11 \\
(100.0 \%)\end{array}$ & \\
\hline \multirow[t]{3}{*}{ Macroscopic type } & Flat and elevated & $\begin{array}{l}16 \\
(29.1 \%)\end{array}$ & $\begin{array}{l}10 \\
(30.3 \%)\end{array}$ & $6(54.4 \%)$ & $0(0.0 \%)$ & \multirow[t]{3}{*}{$<.0001$} \\
\hline & Flat & $\begin{array}{l}5 \\
(9.1 \%)\end{array}$ & $0(0.0 \%)$ & $0(0.0 \%)$ & $5(45.6 \%)$ & \\
\hline & $\begin{array}{l}\text { Flat and } \\
\text { depressed }\end{array}$ & $\begin{array}{l}34 \\
(61.8 \%)\end{array}$ & $\begin{array}{l}23 \\
(69.7 \%)\end{array}$ & $5(45.6 \%)$ & $6(54.4 \%)$ & \\
\hline
\end{tabular}

S group: solitary lesions; $M$ group: EGC with metachronous lesions developing on scars after curable ESD; N group: H. pylori-negative EGC with no atrophic mucosa

EGC, early gastric cancer; ESD, endoscopic submucosal dissection 


\begin{tabular}{|c|c|c|c|c|c|c|}
\hline & & $\begin{array}{l}\text { EGC } \\
(n=55)\end{array}$ & $\begin{array}{l}\text { S group } \\
(n=33)\end{array}$ & $\begin{array}{l}\text { M group } \\
(n=11)\end{array}$ & $\begin{array}{l}\mathrm{N} \text { group } \\
(n=11)\end{array}$ & $\begin{array}{l}P \\
\text { value }\end{array}$ \\
\hline \multirow[t]{4}{*}{ Histological type } & $\begin{array}{l}\text { Well- } \\
\text { differentiated }\end{array}$ & $\begin{array}{l}39 \\
(70.9 \%)\end{array}$ & $\begin{array}{l}29 \\
(87.9 \%)\end{array}$ & $\begin{array}{l}10 \\
(90.9 \%)\end{array}$ & $0(0.0 \%)$ & \multirow[t]{4}{*}{$<.0001$} \\
\hline & $\begin{array}{l}\text { Moderately } \\
\text { differentiated }\end{array}$ & $\begin{array}{l}5 \\
(9.1 \%)\end{array}$ & $4(12.1 \%)$ & $1(9.1 \%)$ & $0(0.0 \%)$ & \\
\hline & $\begin{array}{l}\text { Poorly } \\
\text { differentiated }\end{array}$ & $\begin{array}{l}11 \\
(20.0 \%)\end{array}$ & $0(0.0 \%)$ & $0(0.0 \%)$ & $\begin{array}{l}11 \\
(100.0 \%)\end{array}$ & \\
\hline & $\begin{array}{l}\text { (signet-ring cell } \\
\text { carcinoma) }\end{array}$ & & & & & \\
\hline \multicolumn{7}{|c|}{$\begin{array}{l}\text { S group: solitary lesions; M group: EGC with metachronous lesions developing on scars after curable } \\
\text { ESD; N group: H. pylori-negative EGC with no atrophic mucosa }\end{array}$} \\
\hline \multicolumn{7}{|c|}{ EGC, early gastric cancer; ESD, endoscopic submucosal dissection } \\
\hline
\end{tabular}


Table 2

Clinicopathological characteristics (S group and M group)

\begin{tabular}{|c|c|c|c|c|}
\hline & & $\begin{array}{l}\text { S group } \\
(n=33)\end{array}$ & $\begin{array}{l}\text { M group } \\
(n=11)\end{array}$ & $P$ value \\
\hline Age & Median (range) & $73(58-85)$ & $74(65-84)$ & 0.4319 \\
\hline \multirow[t]{2}{*}{ Sex } & Male & $25(75.8 \%)$ & $7(63.6 \%)$ & \multirow[t]{2}{*}{0.4569} \\
\hline & Female & $8(24.2 \%)$ & $4(36.4 \%)$ & \\
\hline \multirow[t]{2}{*}{ H. pylori status (during ESD) } & Current infection & $12(36.4 \%)$ & $4(36.4 \%)$ & \multirow[t]{2}{*}{1.0000} \\
\hline & After eradication & $21(63.6 \%)$ & $7(63.6 \%)$ & \\
\hline \multirow[t]{2}{*}{ Atrophy } & Closed type & $3(9.1 \%)$ & $1(9.1 \%)$ & \multirow[t]{2}{*}{1.0000} \\
\hline & Open type & $30(90.9 \%)$ & $10(90.9 \%)$ & \\
\hline \multirow[t]{2}{*}{ Location } & Middle & $19(57.6 \%)$ & $7(63.6 \%)$ & \multirow[t]{2}{*}{1.0000} \\
\hline & Low & $14(42.4 \%)$ & $4(36.4 \%)$ & \\
\hline \multirow[t]{2}{*}{ Macroscopic type } & Flat and elevated & $10(30.3 \%)$ & $6(54.4 \%)$ & \multirow[t]{2}{*}{0.1694} \\
\hline & Flat and depressed & $23(69.7 \%)$ & $5(45.6 \%)$ & \\
\hline \multirow[t]{2}{*}{ Histological type } & Well-differentiated & $29(87.9 \%)$ & $10(90.9 \%)$ & \multirow[t]{2}{*}{1.0000} \\
\hline & Moderately differentiated & $4(12.1 \%)$ & $1(9.1 \%)$ & \\
\hline \multicolumn{5}{|c|}{$\begin{array}{l}\text { S group: solitary lesions; M group: EGC with metachronous lesions developing on scars after curable } \\
\text { ESD }\end{array}$} \\
\hline
\end{tabular}

\section{Quantification of CD01 promoter DNA methylation in the S group}

In the S group, the CDO1 TaqMeth values significantly differed between the $\mathrm{T}$ ( $n=33$; median, 26.0; range, 3.1-81.2) and the TAM ( $n=33 \times 4=132$; median, 18.3; range, 0.0-65.8) $(P=0.0006$; Fig. 1-A). The CDO1 TaqMeth values for the TAM were significantly lower than those for the T; however, they were unexpectedly higher than expected. Our recent study on $C D O 1$ methylation status clarified that the methylation value was almost 0 (median, 0 ; range, 0.0-3.4) in 160 cases of the corresponding noncancerous pancreas (non-CP) among patients with pancreatic ductal adenocarcinoma (PDAC).[29] Nevertheless, the noncancerous TAM had significantly higher $C D 01$ TaqMeth values in the S group than in the non-CP group $(P<0.0001$; Fig. 1-A). We subsequently investigated the separated TAMs (4-points: oral TAM, anal TAM, right TAM, and left TAM) in comparison to the corresponding T $(P=0.0111, P=$ $0.0451, P=0.0201$, and $P=0.0220$, respectively; Fig. 1-B). 
In the M group, no significant difference in $C D O 1$ TaqMeth values was identified between the $\mathrm{T}(n=11$; median, 40.1; range, $16.2-85.3)$ and the TAM $(n=11 \times 4=44$; median, 33.2; range, 7.1-100.6) $(P=0.3914$; Fig. 1-C). We subsequently investigated the separated TAMs (4-points: oral TAM, anal TAM, right TAM, and left TAM) in comparison to the corresponding T $(P=0.3606, P=0.9999, P=0.2535$, and $P=0.5242$, respectively; Fig. 1-D).

\section{Quantification of CD01 promoter DNA methylation in the $\mathrm{N}$ group}

CDO1 TaqMeth values were unexpectedly high in both the $\mathrm{S}$ and $\mathrm{M}$ groups, in contrast to the noncancerous pancreas in PDAC patients. Subsequently, those of the $\mathrm{N}$ group were examined and compared with those of either the $\mathrm{S}$ or $\mathrm{M}$ group because the TAM in the $\mathrm{N}$ group might not be considered precancerous.[30] As expected, the TAM in the $\mathrm{N}$ group showed almost 0 CDO1 TaqMeth values, similar to the non-CP. Intriguingly, there was no significant difference in $C D O 1$ TaqMeth values between the T $(n=$ 11; median, 0.0; range, $0.0-2.9)$ and the TAM $(n=11 \times 4=44$; median, 0.0 ; range, $0.0-6.5)(P=0.9338$;

Fig. 1-E). These findings suggest that carcinogenesis in non-atrophic mucosa is mechanistically different from that in atrophic mucosa. We subsequently investigated the separated TAMs (4-points: oral TAM, anal TAM, right TAM, and left TAM $)$ in comparison to the corresponding $\mathrm{T}(P=0.4969, P=0.3155, P=$ 0.5003 , and $P=0.7500$, respectively; Fig. $1-\mathrm{F}$ ).

\section{Unique characteristics of the TAM in the M group}

In the $S+M$ groups, the median TaqMeth values for the T $(n=33+11=44)$ and the TAM $(n=44 \times 4=176)$ were 33.6 (range, 3.1-85.3) and 20.5 (range, 0.0-100.6), respectively. The T was significantly higher than the TAM $(P=0.0019)$, and $C D O 1$ TaqMeth values for the TAM were significantly higher in the $S+M$ groups than in the $\mathrm{N}$ group $(P<0.0001$; Fig. 2-A). Subsequently, we separately analyzed the T (Fig. 2-B) and the TAM (Fig. 2-C) between the $S$ and the M group. The median $C D O 1$ TaqMeth value for the $T$ was 26.0 (range, 3.1-81.2) in the S group $(n=33)$ and 40.1 (range, 16.2-85.3) in the M group $(n=11)$, albeit without significant difference ( $P=0.1096$; Fig. 2-B). The median TaqMeth value for the TAM was 18.3 (range, $0.0-65.8)$ in the $S$ group $(n=132)$ and 33.2 (range, $7.1-100.6)$ in the $\mathrm{M}$ group $(n=44)$, showing a significant difference $(P<0.0001$; Fig. 2-C). Intriguingly, no significant difference was detected between the TAM in the M group and the T in 44 cases in the $S+M$ groups ( $P=0.5713$; Fig. 2-D), whereas the CDO1 TaqMeth values for the TAM were significantly higher in the $S$ and the $\mathrm{M}$ group than in the $\mathrm{N}$ group $(P<0.0001$ and $P<0.0001$, respectively; Fig. 2-D).

\section{Prediction according to the CD01 TaqMeth values in metachronous lesions developing on scars after curable ESD}

The optimal cut-off value for EGC occurrence was analyzed from the TAM in the S and the M groups using the receiver operating characteristic curve for the prediction of metachronous lesions developing on scars after curable ESD. The most optimized TaqMeth value for all TAMs $(n=176)$ in both groups was 29.1 (area under the curve [AUC], 0.74; $P<0.0001$; sensitivity, 56.8\%; specificity, 79.6\%; Fig. 3-A). 
Furthermore, when the highest value for 4-points separated TAMs in both groups was extracted, the most optimized TaqMeth value was 43.4 (AUC, $0.81 ; P<0.0001$; sensitivity, 81.8\%; specificity, 78.8\%; Fig. 3-B).

The CDO1 TaqMeth values in all cases are presented in Fig. 3-C-E, with yellow squares representing points equal to or greater than the cut-off value (43.4) for the TAM. In 9 cases (81.8\%), the highest value for the TAM was equal to or greater than the cut-off value among 11 patients in the $M$ group. In 7 cases (21.2\%), the highest value for the TAM was equal to or greater than the cut-off value among 33 patients in the $\mathrm{S}$ group. This distribution difference was statistically significant $(P<0.0001)$ (Fig. 3-F). The red squares represent points equal to or greater than the cut-off value (43.4) for the T. In 5 cases (45.5\%), the TaqMeth value for $\mathrm{T}$ was equal to or greater than the cut-off value among 11 patients in the $\mathrm{M}$ group, whereas in seven cases $(21.2 \%)$, the TaqMeth value for the T was equal to or greater than the cut-off value among 33 patients in the $S$ group $(P=0.1387)$ (Fig. 3-G).

\section{Discussion}

This is the first study to report the molecular alterations associated with metachronous lesions developing on scars after curable resection by ESD for EGC. EGC with metachronous lesions developing on scars was detected in only $0.5 \%$ of all ESD cases. The median duration for new atypical lesions developing on scars after curable ESD was 22 months (range, 14-49 months). EGC with metachronous lesions developing on scars was compared to EGC with no confirmed evidence of metachronous lesions at $>3$ years after curable ESD (controls), and we identified no clear clinicopathological features between the two groups. Furthermore, H. pylori-negative EGC patients with non-atrophic mucosa differed from controls in several aspects, including age, histological type, macroscopic type, and $H$. pylori status. Therefore, EGC with metachronous lesions developing on scars after curable ESD might have formed as a result of molecular changes in the background atrophic mucosa, and such changes may play a critical role in carcinogenesis among epigenetic factors.

The carcinogenic process in the gastric mucosa with atrophy is mainly attributable to field epigenetic abnormalities.[10] Atrophy related to old age and H. pylori is known to be caused by irritation due to persistent chronic inflammation.[10,31] Chronic inflammation leads to DNA and epigenetic abnormalities in the gastric mucosa.[11, 32] In particular, epigenetic alterations involved in gastric carcinogenesis are considered to contribute to a two-fold higher risk than that of esophageal squamous cell carcinoma,[33] which may be due to the so-called "field cancerization," in which epigenetic changes responsible for gene expression have already occurred in the background gastric mucosa.[12] EGC with metachronous lesions developing on scars after curable ESD was pathologically confirmed after curative resection by ESD and was not caused by residual cancer. Nevertheless, considering the newly developed cancer in the same area, it is strongly suggested that the TAM already harbored cancer-like changes. We focused our attention on $C D O 1$, a hypermethylated gene with particularly high specificity in human cancers, because $C D O 1$ is the most promising candidate gene for cancer-specific epigenetic changes. 
Among the cancer-specific methylation genes in gastric cancer, CDO1 has the highest AUC (0.95), which distinguishes cancerous from noncancerous tissues.[14] This finding suggests that $C D O 1$ methylation in cancer cells may be strongly associated with carcinogenesis. The current study revealed that the TAM in EGC was hypermethylated, albeit not as much as the tumor (Fig. 1-A). Our previous study on CDO1 methylation in PDAC showed that $90 \%$ of cancerous tissues were methylated, whereas non-CP exhibited no methylation.[29] Additionally, in remnant gastric cancer, $C D O 1$ was more highly methylated in cancerous tissue than in the noncancerous mucosa, which is far from the tumor; however, its methylation level was clearly detected in the noncancerous mucosa.[34] Furthermore, CDO1 methylation has been reported to be significantly higher in precancerous lesions of other cancers such as small bowel cancer, colorectal cancer, and intraductal papillary mucinous neoplasm than in noncancerous tissues. [24, 25, 35] In our study, for the first time, we demonstrated that CDO1 hypermethylation in the TAM was more frequently detected in EGC with metachronous lesions developing on scars than in EGC with no evidence of metachronous lesions. Moreover, using the optimal CDO1 methylation value (43.4), we identified as many as nine out of 11 cases of EGC with metachronous lesions developing on scars after curable ESD. Therefore, our study confirmed that the TAM in EGC with metachronous lesions developing on scars exhibited cancer patterns.

Since EGC with metachronous lesions developing on scars after curable ESD is extremely rare, even if this prediction is possible, it may not have a significant clinical impact. Nonetheless, this is considered extremely useful as a model to investigate the carcinogenesis of gastric cancer. In our study, we believe that this is a very important finding, as the result of EGC with metachronous lesions developing on scars reflects epigenetic abnormalities that had already occurred. Regarding prediction of EGC, Asada et al. examined gene methylation at a fixed point in the antrum (the lesser curvature at $2 \mathrm{~cm}$ from the pyloric ring) and reported a 2.3-fold increased risk of heterogeneous gastric cancer.[36] However, with respect to the prediction of EGC with metachronous lesions developing on non-scar tissue, identifying the site of development with gastric cancer is difficult, and the site of development cannot be accurately determined by prior biopsy. In contrast, measurement of CDO1 methylation in ESD tissue for the T and the TAM may predict the occurrence of new cancers in scars after treatment. For this reason, metachronous lesions developing on scars after curable ESD may be an important design model for predicting the development of EGC.

Surprisingly, EGC cases without atrophy ( $\mathrm{N}$ group) showed no CDO1 methylation in the TAM or even in the tumor. As the age of carcinogenesis in these cases is younger than that in conventional gastric cancer, there exists the possibility that de novo carcinogenesis is more likely to generate such a specific gastric cancer than epigenetic carcinogenesis. In our study, the histological types of $H$. pylori-negative EGC with no atrophic mucosa ( $\mathrm{N}$ group) were all signet-ring cells, whereas advanced tumors with signet-ring cell histology exhibited $C D O 1$ hypermethylation, similar to other histological types.[20] This finding suggests that $C D O 1$ methylation does not occur in EGC with signet-ring histology that remains within the mucosa. To more accurately determine this, further pathological analysis of $C D O 1$ hypermethylation is necessary. 
Our study has several important limitations. We analyzed the methylation of a single gene, CDO1. DNA methylation is not a change that occurs in only a single gene; there is a strong association between methylated genes.[37] We have recently reported that when combined with HOPX/Reprimo/CDH1, CDO1 methylation can predict future occurrences of remnant gastric cancer.[34] Therefore, other methylated genes should be considered in combination with $C D O 1$ in order to develop a more accurate system for prediction and clinical application. Furthermore, in the present study, using EGCs with metachronous lesions were not identified more than 3 years after curable ESD as a control, the optimal methylation value of $C D O 1$ (43.4) was used to identify 9 of 11 cases of EGC with metachronous lesions developing on the scar after curable ESD. However, among the EGC in which metachronous lesions were not identified at least more than 3 years after ESD, we found seven cases with high CDO1 methylation of the TAM. These cases need to be closely monitored owing to the possibility of new lesions development on the scar.

In conclusion, $C D O 1$ promoter DNA methylation may be an important biomarker for predicting EGC with metachronous lesions developing on scars after curable ESD. If an accurate system can be developed to predict EGC with metachronous lesions developing on scars after curable ESD in the near future, molecular information on lesions after radical ESD will be a new index to propose the most optimal follow-up endoscopy program after ESD treatment.

\section{Methods}

\section{Patients}

A total of 2,055 patients underwent ESD for EGC at Kitasato University Hospital and Kitasato University East Hospital from September 2002 to December 2016 (Fig. 4). Of these 2055 patients, 11 (0.5\%) patients had EGC with metachronous lesions developing on scars after curable ESD (M group) (Fig. 5-A). All 11 patients were positive for $\mathrm{H}$. pylori (current infection or after eradication).

A total of 33 patients with the latest consecutive EGC who had no confirmed evidence of metachronous lesions at > 3 years after curable ESD (solitary [S] group) were selected as controls from 1896 patients with no metachronous lesions. All 33 patients were positive for $\mathrm{H}$. pylori (current infection or after eradication).

Additionally, 11 patients with the latest consecutive $\mathrm{H}$. pylori-negative EGC who had no atrophic mucosa (EGC with no confirmed atrophic mucosa: $\mathrm{N}$ group) were selected as negative controls (Fig. 5-B). The $\mathrm{N}$ group was also defined as EGC with gastric mucosa with all of the following three findings: (1) negative results for urea breath test or serum IgG antibody to $\mathrm{H}$. pylori; (2) no gastric mucosal atrophy with a regular arrangement of collecting venules at the antrum, as revealed by upper gastrointestinal endoscopy[38]; and (3) no atrophy or intestinal metaplasia on pathological findings with mild mononuclear infiltration, no neutrophil infiltration, and no $\mathrm{H}$. pylori based on the updated Sydney system. [39] 
This study was conducted in accordance with the ethical guidelines outlined in the Declaration of Helsinki and was approved by the Kitasato University Hospital Ethics Committee (no. B18-036). All patients provided informed consent.

\section{Cell lines}

The hepatocellular carcinoma cell line HepG2 and colorectal cancer cell line DLD1 were used as positive and negative controls for CDO1 methylation, as previously described.[28] The DLD1 cells were provided by the Cell Resource Center for Biomedical Research, Institute of Development, Aging and Cancer, Tohoku University (Sendai, Japan), whereas the HepG2 cells were purchased from RIKEN BioResource Research Center (Ibaraki, Japan). The DLD1 cells were maintained in Roswell Park Memorial Institute-1640 medium (Gibco, Carlsbad, CA, USA). The HepG2 cells were maintained in Dulbecco's modified Eagle's medium (GIBCO) containing $10 \%$ fetal bovine serum and penicillin-streptomycin (GIBCO).

\section{Genomic DNA extraction and bisulfite treatment}

The tumor (T) and the TAM were identified using EGC specimens pathologically diagnosed using hematoxylin-eosin staining after ESD. Formalin-fixed paraffin-embedded tissues of excised specimens were cut into $2010-\mu \mathrm{m}$-thick slices prepared for the T and the TAM sections. After deparaffinization, genomic DNA was extracted from the T and the separated TAMs (4-points: oral TAM, anal TAM, right TAM, and left TAM) tissues using the QIAamp DNA Mini Kit (Qiagen, Hilden, Germany) (Fig. 6). The extracted genomic DNA $(2 \mu \mathrm{g})$ was chemically converted by bisulfite treatment using the EZ DNA Methylation-Gold ${ }^{\text {TM }}$ Kit (Zymo Research, Irvine, CA, USA). The bisulfited DNA was subsequently amplified as templates by quantitative methylation-specific polymerase chain reaction (Q-MSP).

\section{Q-MSP}

Q-MSP for CD01 was performed using the $\mathrm{C} 1000$ Touch $^{\text {TM }}$ Thermal Cycler with the CFX96 Real-Time System (Bio-Rad, Hercules, CA, USA). Q-MSP was conducted at $95^{\circ} \mathrm{C}$ for $3 \mathrm{~min}$, followed by 40 cycles at $95^{\circ} \mathrm{C}$ for $20 \mathrm{~s}$, annealing temperature for $30 \mathrm{~s}$, and $72^{\circ} \mathrm{C}$ for $30 \mathrm{~s}$, in a $25-\mu \mathrm{L}$ reaction volume containing 1 $\mu \mathrm{L}$ of bisulfite-treated genomic DNA, $300 \mathrm{nmol} / \mathrm{L}$ of each primer, $200 \mathrm{nmol} / \mathrm{L}$ of a fluorescent probe, and $12.5 \mu \mathrm{L}$ of iQ Supermix (Bio-Rad). PCR conditions and sequences of primers and probe were designed, as previously described.[40] All reactions were performed in triplicate. CDO1 methylation value was defined as the ratio of the amplified signal value of methylated CDO1 to the value for $\beta$-actin, which was subsequently multiplied by 100 . The CDO1 methylation value was designated as the TaqMeth value throughout the text.

\section{Statistical analysis}

Continuous and categorical variables were analyzed using Student's t-test and the $\chi 2$ test, respectively. Univariate analyses of factors for the clinicopathological characteristics of EGC were performed using the log-rank method. The observation period was defined as the time from the first ESD day to the final upper gastrointestinal endoscopy day (median, 55.5 months; range, 2-152 months. The median observation 
period was 59 months (range, 37-66 months) in the S group, 68 months (range, 44-152 months) in the $\mathrm{M}$ group, and 18 months (range, 2-52 months) in the $\mathrm{N}$ group. The occurrence period with metachronous lesions was defined as the time from the first ESD day to the second ESD day (median, 22 months; range, 14-49 months). Statistical analyses were performed using JMP 11 software (SAS Institute Inc., Cary, NC, USA). P-value $<0.05$ was considered to indicate statistical significance.

\section{Declarations}

\section{Acknowledgments}

The authors would like to thank Editage Cactus Communications, Tokyo Japan, for proofreading the manuscript.

\section{AUTHOR CONTRIBUTIONS STATEMENT}

Y.K. was responsible for the concept and design, collection and assembly of data, and statistical analysis. M.A. collected and assembled the data. H.K., Y.F. and T.S. analyzed and interpreted the data. Y.F., T.W., A.W., K.I., C.K., K.Y. and W.K. contributed to data collection and critically reviewed the manuscript. S.T. was the general director of the study group. All authors read and gave final approval to the manuscript.

\section{Additional Information}

\section{Funding}

This study was funded by a Parents' Association Grant of Kitasato University, School of Medicine

\section{Correspondence}

Yo Kubota

Department of Gastroenterology, Kitasato University School of Medicine 1-15-1 Kitasato, Minami-ku, Sagamihara, Kanagawa 252-0375, Japan

Phone: +81-42-778-8111 (Japan); Fax: +81-42-778-8390 (Japan)

E-mail: kubota@kitasato-u.ac.jp

\section{ORCID iD}

Yo Kubota: 0000-0002-4050-396X

\section{Conflicts of interest/Competing interests}


I declare that the authors have no competing interests as defined by Nature Research or other interests that might be perceived to influence the results and/or discussion reported in this paper.

\section{Ethics approval}

This study was approved by the Kitasato University Hospital Ethics Committee (no. B18-036).

\section{Consent to participate}

The study was conducted following the Declaration of Helsinki and after obtaining approval of the institutional research ethics committee and written informed consent obtained from all participants.

\section{Consent for publication}

The manuscript does not contain clinical studies or patient data.

\section{Code availability}

Available upon request

\section{Availability of materials and data}

The technical appendix, statistical code, and dataset are available from the corresponding author.

\section{References}

1. Rohrmann, S. et al. Meat and fish consumption and the risk of renal cell carcinoma in the European prospective investigation into cancer and nutrition. Int. J. Cancer, 136, E423-E431 (2015).

2. Hori, M. et al. Cancer incidence and incidence rates in Japan in 2009: a study of 32 population-based cancer registries for the Monitoring of Cancer Incidence in Japan (MCIJ) project. Jpn. J. Clin. Oncol, 45, 884-891 (2015).

3. Japanese Gastric Cancer Association. Japanese gastric cancer treatment guidelines 2018 (5th edition). Gastric. Cancer. 24, 1-21 (2021).

4. Fukase, K. et al. Effect of Helicobacter pylori eradication on the incidence of metachronous gastric carcinoma after endoscopic resection of early gastric cancer: an open-label, randomized controlled trial. Lancet, 372, 392-397 (2008).

5. Kamada, T. et al. Clinical features of gastric cancer discovered after successful eradication of Helicobacter pylori: results from a 9-year prospective follow-up study in Japan. Aliment. Pharmacol. Ther, 21, 1121-1126 (2005).

6. Mori, G. et al. Incidence of and risk factors for metachronous gastric cancer after endoscopic resection and successful Helicobacter pylori eradication: results of a large-scale, multicenter cohort study in Japan. Gastric. Cancer, 19, 911-918 (2006). 
7. Oka, S. et al. Advantage of endoscopic submucosal dissection compared with EMR for early gastric cancer. Gastrointest. Endosc, 64, 877-883 (2006).

8. Cancer Genome Atlas Research Network. Comprehensive molecular characterization of gastric adenocarcinoma. Nature, 513, 202-209 (2014).

9. Yamashita, S. et al. Genetic and epigenetic alterations in normal tissues have differential impacts on cancer risk among tissues. Proc. Natl. Acad. Sci. USA. 115, 1328-1333(2018).

10. Niwa, T. et al. Inflammatory processes triggered by Helicobacter pylori infection cause aberrant DNA methylation in gastric epithelial cells. Cancer. Res, 70, 1430-1440 (2010).

11. Maekita, T. et al. High levels of aberrant DNA methylation in Helicobacter pylori-infected gastric mucosae and its possible association with gastric cancer risk. Clin. Cancer. Res, 12, 989-995 (2006).

12. Ushijima, T. \& Hattori, N. Molecular pathways: involvement of Helicobacter pylori-triggered inflammation in the formation of an epigenetic field defect, and its usefulness as cancer risk and exposure markers. Clin. Cancer. Res, 18, 923-929 (2012).

13. Ushijima, T. \& Asada, K. Aberrant DNA methylation in contrast with mutations. Cancer. Sci, 101, 300305 (2010).

14. Yamashita, K., Hosoda, K., Nishizawa, N., Katoh, H. \& Watanabe, M. Epigenetic biomarkers of promoter DNA methylation in the new era of cancer treatment. Cancer. Sci, 109, 3695-3706 (2018).

15. Ooki, A., Yamashita, K., Kikuchi, S., Katoh, H. \& Watanabe, M. Potential utility of HOP homeobox gene promoter methylation as a marker of tumor aggressiveness in gastric cancer. Oncogene, 29, 32633275 (2010).

16. Yamashita, K. et al. Pharmacologic unmasking of epigenetically silenced tumor suppressor genes in esophageal squamous cell carcinoma. Cancer. Cell, 2, 485-495 (2002).

17. Brait, M. et al. Cysteine dioxygenase 1 is a tumor suppressor gene silenced by promoter methylation in multiple human cancers. PLoS. One, 7, e44951 (2012).

18. Ishimoto, T. et al. CD44 variant regulates redox status in cancer cells by stabilizing the XCT subunit of system xc(-) and thereby promotes tumor growth. Cancer. Cell, 19, 387-400 (2011).

19. Kang, Y. P. et al. Cysteine dioxygenase 1 is a metabolic liability for non-small cell lung cancer. Elife, 8 , e45572 (2019).

20. Harada, H. et al. Cancer-specific promoter DNA methylation of cysteine dioxygenase type 1 (CD01) gene as an important prognostic biomarker of gastric cancer. PLoS. One, 14, e0214872 (2019).

21. Ushiku, H. et al. DNA diagnosis of peritoneal fluid cytology test by CDO1 promoter DNA hypermethylation in gastric cancer. Gastric. Cancer, 20, 784-792 (2017).

22. Ushiku, H. et al. Promoter DNA methylation of CDO1 gene and its clinical significance in esophageal squamous cell carcinoma. Dis. Esophagus, 30, 1-9 (2017).

23. Kojima, K. et al. The clinical significance of cysteine dioxygenase type 1 methylation in Barrett esophagus adenocarcinoma. Dis. Esophagus, 30, 1-9 (2017). 
24. Kojima, K. et al. Clinical significance of cancer specific methylation of the CDO1 gene in small bowel cancer. PLoS. One, 14, e0211108 (2019).

25. Kojima, K. et al. Cysteine dioxygenase type 1 (CDO1) gene promoter methylation during the adenoma-carcinoma sequence in colorectal cancer. PLoS. One, 13, e0194785 (2018).

26. Kimura, K. \& Takemoto, T. An endoscopic recognition of the atrophic border and its significance in chronic gastritis. Endoscopy, 1, 87-97 (1969).

27. Kimura, K. et al. Gastritis in the Japanese stomach. Scand. J. Gastroenterol. Suppl, 214, 17-20 (1996).

28. Quach, D. T. \& Hiyama, T. Assessment of endoscopic gastric atrophy according to the KimuraTakemoto classification and its potential application in daily practice. Clin. Endosc. 2019;52: 321327 (2019).

29. Nishizawa, N. et al. Diagnostic potential of hypermethylation of the cysteine dioxygenase 1 gene (CD01) promoter DNA in pancreatic cancer. Cancer. Sci, 110, 2846-2855 (2019).

30. Uemura, N. et al. Helicobacter pylori infection and the development of gastric cancer. N. Engl. J. Med, 345, 784-789 (2001).

31. Issa, J. P. et al. Methylation of the oestrogen receptor $\mathrm{CpG}$ island links ageing and neoplasia in human colon. Nat. Genet, 7, 536-540 (1994).

32. Ando, T. et al. DNA methylation of microRNA genes in gastric mucosae of gastric cancer patients: its possible involvement in the formation of epigenetic field defect. Int. J. Cancer, 124, 2367-2374 (2009).

33. Yamashita, S. et al. Genetic and epigenetic alterations in normal tissues have differential impacts on cancer risk among tissues. Proc. Natl. Acad. Sci. USA. 115, 1328-1333(2018).

34. Kojima, K. et al. Prediction of onset of remnant gastric cancer by promoter DNA methylation of CD01/HOPX/Reprimo/E-cadherin. Oncotarget, 10, 2423-2434 (2019).

35. Fujiyama, Y. et al. Promoter DNA hypermethylation of the cysteine dioxygenase 1 (CD01) gene in intraductal papillary mucinous neoplasm (IPMN). Ann. Surg. Oncol, 27, 4007-4016 (2020).

36. Asada, K. et al. Demonstration of the usefulness of epigenetic cancer risk prediction by a multicentre prospective cohort study. Gut, 64, 388-396 (2015).

37. Toyota, M. et al. Aberrant methylation in gastric cancer associated with the $\mathrm{CpG}$ island methylator phenotype. Cancer Res, 59, 5438-5442 (1999).

38. Yagi, K., Aruga, Y., Nakamura, A. \& Sekine, A. Regular arrangement of collecting venules (RAC): a characteristic endoscopic feature of Helicobacter pylori-negative normal stomach and its relationship with esophago-gastric adenocarcinoma. J. Gastroenterol, 40, 443-452 (2005).

39. Dixon, M. F., Genta, R. M., Yardley, J. H. \& Correa, P. Classification and grading of gastritis. The updated Sydney System. International Workshop on the Histopathology of Gastritis, Houston 1994. Am. J. Surg. Pathol. 20, 1161-1181(1996). 
40. Yamashita, K. et al. Detection of methylated CDO1 in plasma of colorectal cancer: a PCR study. PLoS. One, 9, e113546 (2014).

\section{Figures}
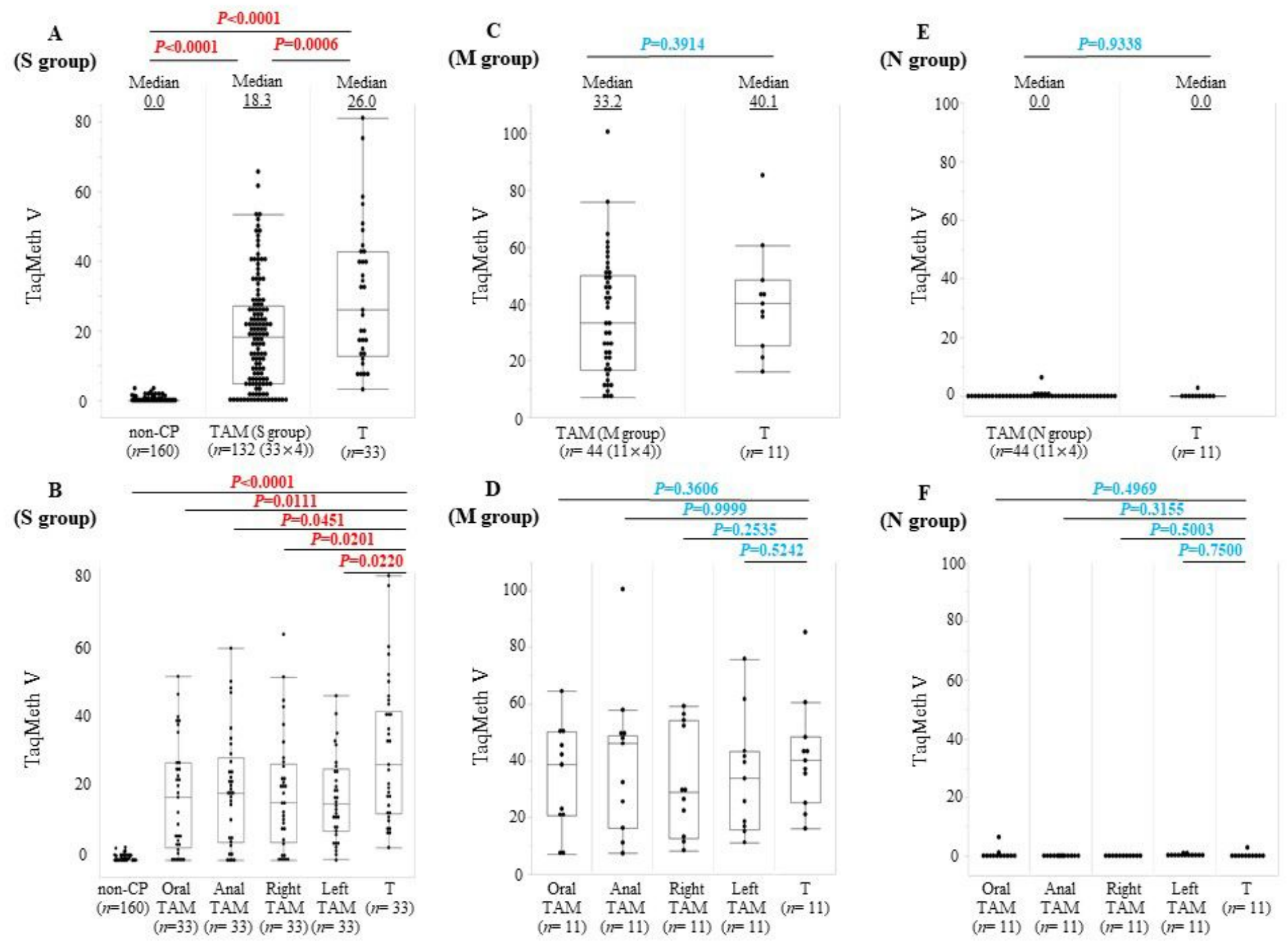

Figure 1

Quantitative methylation-specific polymerase chain reaction for cysteine dioxygenase type 1 (CD01) in the tumor (T) and the tumor-adjacent noncancerous mucosa (TAM) in early gastric cancer (EGC) a. In the $S$ group, there is a significant difference of TaqMeth values of $C D 01$ between the T and the TAM $(P=0.0006)$. TaqMeth values of $C D 01$ of the TAM in the $S$ group are significantly higher than that of the noncancerous pancreas (non-CP) $(P=0.0001)$. b: TaqMeth values of $C D 01$ for the $T$ and the separated TAMs (4-points: oral TAM, anal TAM, right TAM, and left TAM) in the $S$ group. Each point is identified to be significant. ( $P=0.0111, P=0.0451, P=0.0201$, and $P=0.0220$, respectively). $c$ : In the $M$ group, there is no significant difference of TaqMeth values of CDO1 between the T and the TAM ( $P=0.3914)$. $d$ : TaqMeth values of CDO1 for the T and the separated TAMs (oral TAM, anal TAM, right TAM, and left TAM) in the M 
group. None of the points are significantly different. $(P=0.3606, P=0.9999, P=0.2535$, and $P=0.5242$, respectively). e: In the $\mathrm{N}$ group, there is no significant difference of TaqMeth values of CDO1 between the $T$ and the TAM ( $P=0.9338)$. $f$ : TaqMeth values of CD01 for the T and the separated TAMs (oral TAM, anal TAM, right TAM, and left TAM) in the $\mathrm{N}$ group. None of the points are significantly different. $(P=0.4969$, $P=0.3155, P=0.5003$, and $P=0.7500$, respectively). non-CP, noncancerous pancreas; $T$, tumor; TAM, tumoradjacent noncancerous mucosa; $S$ group: solitary lesions; M group: EGC with metachronous lesions developing on scars after curable submucosal dissection; $\mathrm{N}$ group: $\mathrm{H}$. pylori-negative EGC with no atrophic mucosa

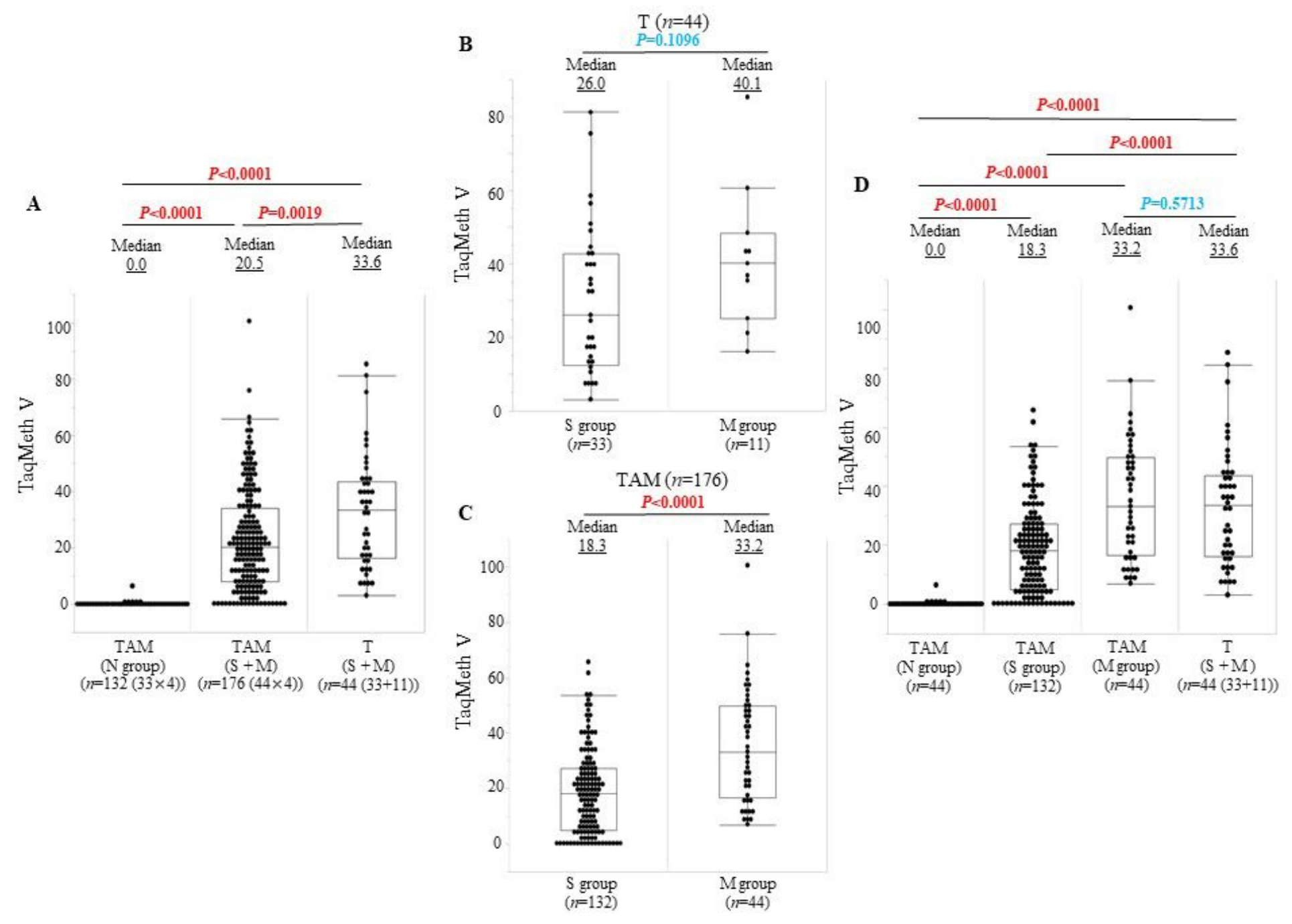

Figure 2

Quantitative methylation-specific polymerase chain reaction for cysteine dioxygenase type 1 (CD01) between the $S$ and $M$ groups in early gastric cancer (EGC) a. In the $S+M$ group, there is a significant difference of TaqMeth values of CDO1 between the T and the TAM $(P=0.0019)$. TaqMeth values of CDO1 for the $T$ and the TAM in the $S+M$ group are significantly higher than the TAM in the $N$ group $(P<0.0001$ and $P<0.0001$, respectively). $b$. In the $T$, there is no significant difference of TaqMeth value of CD01 between the $S$ group and $M$ group $(P=0.1096)$. C. In the TAM, TaqMeth values of CDO1 in the $M$ group are 
significantly higher than in the $S$ group $(P<0.0001)$. $d$. There is no significant difference in TaqMeth values of $C D 01$ between the $T$ in the $S+M$ group and the TAM in the M group ( $P=0.5713)$. The TaqMeth value of $\mathrm{CDO} 1$ for the $\mathrm{T}$ in the $\mathrm{S}+\mathrm{M}$ group is significantly higher than the TAM in the $\mathrm{S}$ group and the $\mathrm{N}$ group ( $P<0.0001$ and $P<0.0001$, respectively). The TaqMeth value of $C D 01$ for the TAM in the $M$ group is significantly higher than the TAM in the $S$ group and the $N$ group $(P<0.0001$ and $P<0.0001$, respectively). T, tumor; TAM, tumor-adjacent noncancerous mucosa; $S$ group: solitary lesions; $M$ group: EGC with metachronous lesions developing on scars after curable endoscopic submucosal dissection; $\mathrm{N}$ group: $\mathrm{H}$. pylori-negative EGC with no atrophic mucosa

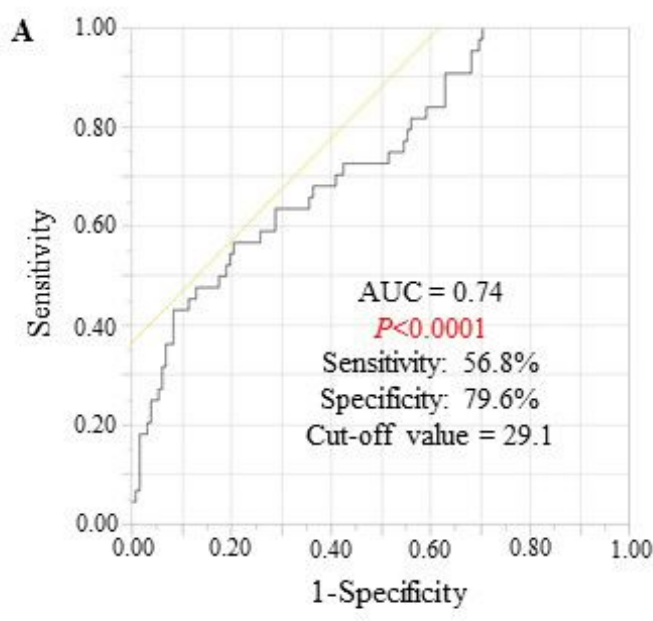

\begin{tabular}{c|ccccc}
\multicolumn{7}{c}{ C (S group) } \\
\hline Case & Oral & Anal & Right & Left & T \\
& TAM & TAM & TAM & TAM & \\
\hline 1 & 53.6 & 52.1 & 65.8 & 16.5 & 40.0 \\
2 & 10.4 & 50.1 & 53.4 & 45.0 & 75.4 \\
3 & 23.1 & 20.3 & 46.5 & 18.3 & 58.5 \\
4 & 0.0 & 61.8 & 9.4 & 7.4 & 56.4 \\
5 & 41.6 & 0.0 & 44.6 & 12.6 & 26.0 \\
6 & 37.2 & 48.9 & 34.5 & 20.1 & 14.8 \\
7 & 48.3 & 35.5 & 19.5 & 25.7 & 34.4 \\
8 & 40.3 & 38.5 & 23.9 & 21.2 & 81.2 \\
9 & 4.7 & 5.6 & 5.4 & 13.6 & 50.9 \\
10 & 28.5 & 25.4 & 11.1 & 34.3 & 49.0 \\
11 & 26.4 & 28.6 & 23.4 & 34.2 & 44.6 \\
12 & 28.2 & 11.7 & 28.6 & 26.0 & 42.7 \\
13 & 0.0 & 18.4 & 16.4 & 20.4 & 20.3 \\
14 & 0.0 & 22.9 & 12.4 & 40.1 & 17.5 \\
15 & 6.7 & 24.1 & 16.8 & 12.4 & 17.1 \\
16 & 39.5 & 16.1 & 22.1 & 2.4 & 32.8 \\
17 & 5.6 & 21.7 & 13.2 & 9.3 & 12.5 \\
18 & 0.3 & 1.7 & 10.7 & 4.3 & 7.3 \\
19 & 1.9 & 22.2 & 27.3 & 4.3 & 39.9 \\
20 & 26.5 & 19.3 & 21.7 & 27.3 & 39.6 \\
21 & 13.9 & 4.2 & 0.0 & 15.3 & 7.8 \\
22 & 21.6 & 26.0 & 39.5 & 4.5 & 12.6 \\
23 & 0.2 & 4.5 & 0.1 & 9.0 & 10.5 \\
24 & 19.5 & 33.8 & 21.0 & 33.6 & 42.9 \\
25 & 0.0 & 0.0 & 0.0 & 1.6 & 3.1 \\
26 & 2.9 & 0.1 & 8.8 & 12.5 & 7.6 \\
27 & 6.6 & 0.0 & 0.8 & 0.0 & 7.3 \\
28 & 23.7 & 19.4 & 29.8 & 23.1 & 11.4 \\
29 & 18.3 & 19.6 & 21.9 & 14.7 & 17.6 \\
30 & 40.4 & 16.7 & 0.0 & 27.7 & 24.5 \\
31 & 4.3 & 1.7 & 1.0 & 3.7 & 19.7 \\
32 & 7.5 & 6.4 & 4.7 & 18.1 & 32.3 \\
33 & 24.2 & 30.9 & 1.2 & 8.1 & 35.9 \\
\hline & & & & & \\
& & & & &
\end{tabular}

\begin{tabular}{|c|c|c|c|c|c|}
\hline \multicolumn{6}{|c|}{ D (M group) } \\
\hline Case & $\begin{array}{l}\text { Oral } \\
\text { TAM }\end{array}$ & $\begin{array}{l}\text { Anal } \\
\text { TAM }\end{array}$ & $\begin{array}{l}\text { Right } \\
\text { TAM }\end{array}$ & $\begin{array}{l}\text { Left } \\
\text { TAM }\end{array}$ & T \\
\hline 1 & 64.6 & 57.9 & 52.4 & 75.9 & 60.6 \\
\hline 2 & 50.3 & 100.6 & 29.1 & 61.7 & 853 \\
\hline 3 & 50.5 & 46.2 & 54.3 & 39.5 & 36.7 \\
\hline 4 & 38.7 & 48.8 & 59.3 & 33.9 & 48.4 \\
\hline 5 & 20.7 & 47.1 & 30.6 & 11.3 & 25.2 \\
\hline 6 & 8.1 & 48.2 & 22.6 & 41.7 & 16.2 \\
\hline 7 & 45.6 & 11.2 & 26.6 & 17.0 & 21.1 \\
\hline 8 & 42.3 & 7.5 & 56.5 & 15.2 & 40.1 \\
\hline 9 & 21.4 & 25.7 & 8.4 & 43.4 & 35.5 \\
\hline 10 & 7.1 & 16.4 & 11.6 & 15.8 & 43.5 \\
\hline 11 & 23.1 & 32.6 & 12.8 & 25.8 & 43.4 \\
\hline \multicolumn{6}{|c|}{ E (N group) } \\
\hline Case & $\begin{array}{c}\text { Oral } \\
\text { TAM }\end{array}$ & $\begin{array}{l}\text { Anal } \\
\text { TAM }\end{array}$ & Right & Left & T \\
\hline 1 & 0.2 & 0.1 & 0.4 & 0.0 & 0.0 \\
\hline 2 & 0.0 & 0.0 & 0.0 & 0.0 & 0.0 \\
\hline 3 & 0.3 & 0.2 & 0.5 & 0.3 & 0.2 \\
\hline 4 & 0.0 & 0.0 & 0.0 & 1.2 & 0.0 \\
\hline 5 & 6.5 & 0.0 & 0.0 & 0.0 & 0.0 \\
\hline 6 & 0.0 & 0.0 & 0.0 & 0.0 & 0.0 \\
\hline 7 & 0.0 & 0.0 & 0.0 & 0.0 & 0.0 \\
\hline 8 & 0.0 & 0.0 & 0.0 & 0.0 & 0.0 \\
\hline 9 & 1.2 & 0.2 & 0.5 & 0.9 & 2.9 \\
\hline 10 & 0.0 & 0.0 & 0.0 & 0.0 & 0.0 \\
\hline 11 & 0.0 & 0.0 & 0.0 & 0.0 & 0.3 \\
\hline \multicolumn{6}{|c|}{ F (TAM) } \\
\hline & & & High & Total & Fande \\
\hline
\end{tabular}

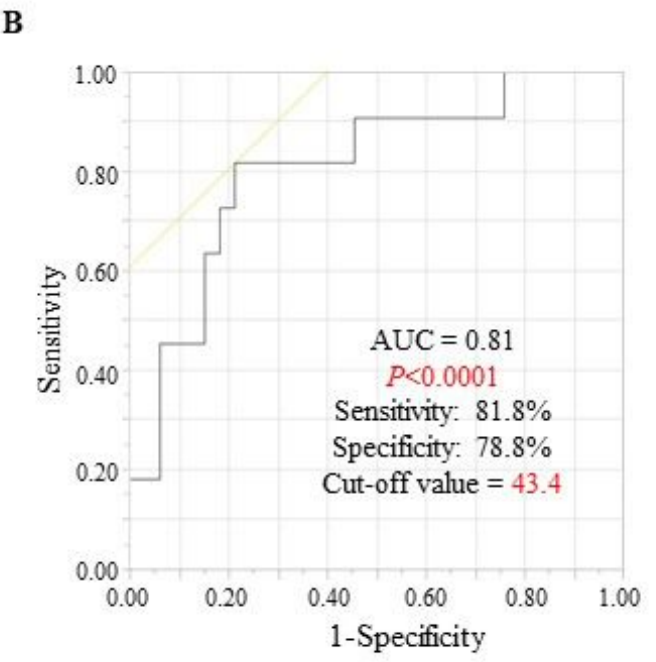

\begin{tabular}{rrrr} 
M group 2(18.2\%) & $9(81.8 \%)$ & 11 & $P<0.0001$ \\
S group 26(78.8\%) & $7(21.2 \%)$ & 33 & \\
\hline & G (T) & & \\
\hline Low & High & Total $P$ value \\
\hline
\end{tabular} M group 6(54.5\%) 5(45.5\%) 11 S group $26(78.8 \%) 7(21.2 \%) \quad 33$

$P=0.1387$

Cut-off value $=\mathbf{4 3 . 4}$

\section{Figure 3}

Quantitative methylation-specific polymerase chain reaction for cysteine dioxygenase type 1 (CDO1) in all points and the optimal cut-off value for early gastric cancer (EGC) occurrence a. Receiver operating characteristic (ROC) curve for all TAMs (S and M groups). The area under the curve (AUC) is 0.74 , and there is a significant difference $(P<0.0001)$. b. ROC curve with the highest value for 4-points separated TAMs ( $\mathrm{S}$ and $\mathrm{M}$ groups). The AUC is 0.81 , and there is a significant difference $(P<0.0001)$. c. All points for the $S$ group are shown. Yellow (TAM) and red squares (T) indicate high CDO1 methylation beyond 43.4. $d$. 
All points for the $\mathrm{M}$ group are shown. Yellow (TAM) and red squares (T) indicate high CD01 methylation beyond 43.4. e. All points for the $\mathrm{N}$ group are shown. Yellow (TAM) and red squares (T) indicate high CD01 methylation beyond 43.4. f. In 11 cases of the M group, 9 cases (81.8\%) show high methylation, whereas seven $(21.2 \%)$ show high methylation in the 33 cases of the $S$ group, and there is a significant difference $(P<0.0001)$. g. In 11 cases of the $M$ group, five cases $(45.5 \%)$ show high methylation, whereas seven $(21.2 \%)$ show high methylation in the 33 cases of the $S$ group, and there is no significant difference $(P=0.1387)$. T, tumor; TAM, tumor-adjacent noncancerous mucosa; $S$ group: solitary lesions; $M$ group: EGC with metachronous lesions developing on scars after curable submucosal dissection; $\mathrm{N}$ group: $\mathrm{H}$. pylori-negative EGC with no atrophic mucosa

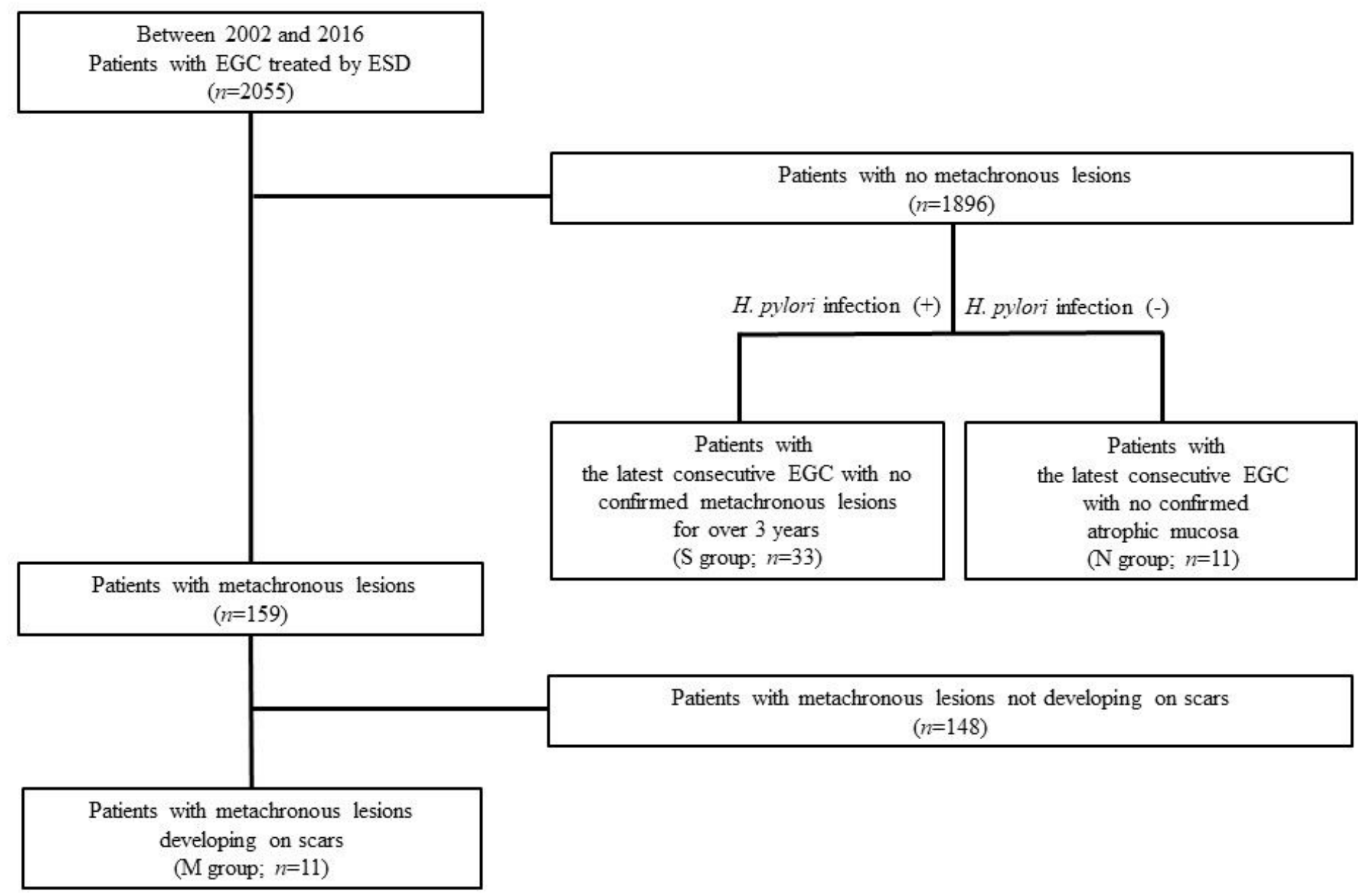

Figure 4

Flowchart for early gastric cancer treated by submucosal dissection 
A

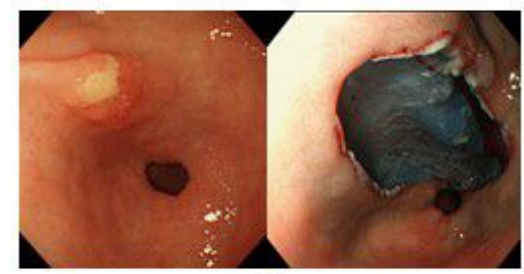

After 3 years

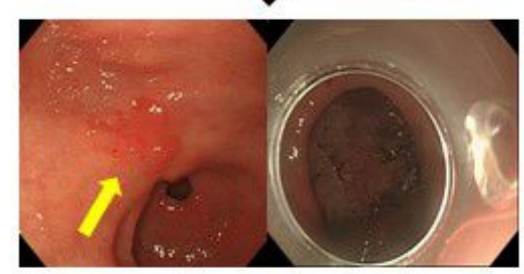

B

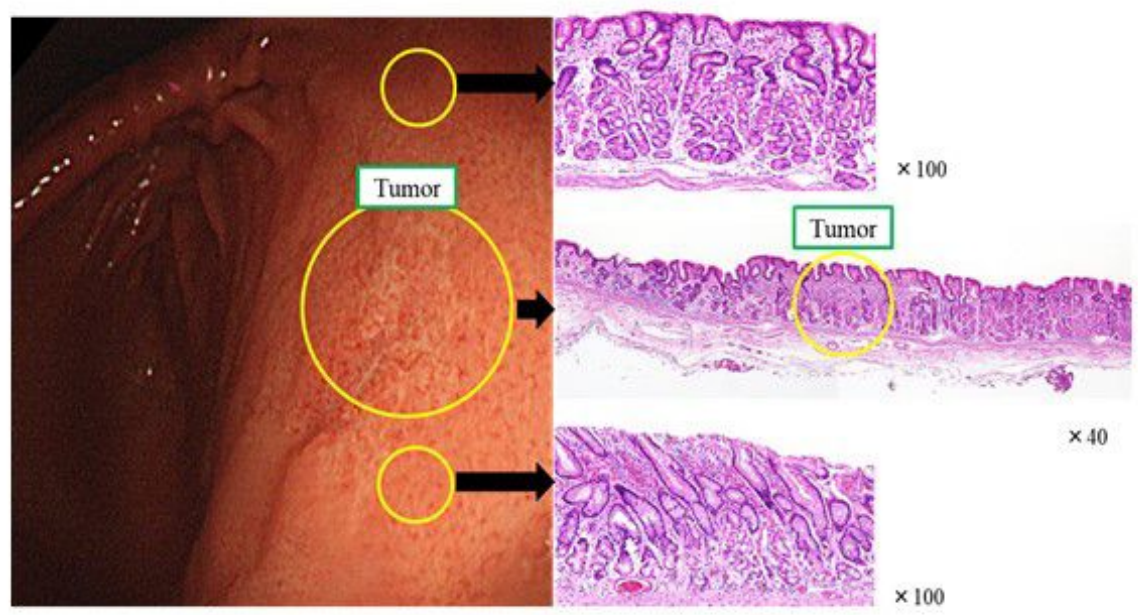

\section{Figure 5}

Representative cases in the M group and $\mathrm{N}$ group a. Representative case of the $\mathrm{M}$ group. At 3 years after the first endoscopic submucosal dissection (ESD) (the left upper panel shows lesion before ESD and the right upper panel is after ESD), we have diagnosed the new lesion (left lower panel) as a metachronous lesion developing on the scar (yellow arrowhead). The right lower panel shows the lesion after the second ESD. b. Representative case of the $\mathrm{N}$ group. There is no atrophy and intestinal metaplasia on endoscopic (left panel) and pathological findings (right panel); there is mild mononuclear infiltration with no neutrophil infiltration, and $\mathrm{H}$. pylori is not detected. T, tumor; TAM, tumor-adjacent noncancerous mucosa; $M$ group: early gastric cancer with metachronous lesions developing on scars after curable ESD; $N$ group: H. pylori-negative EGC with no atrophic mucosa 


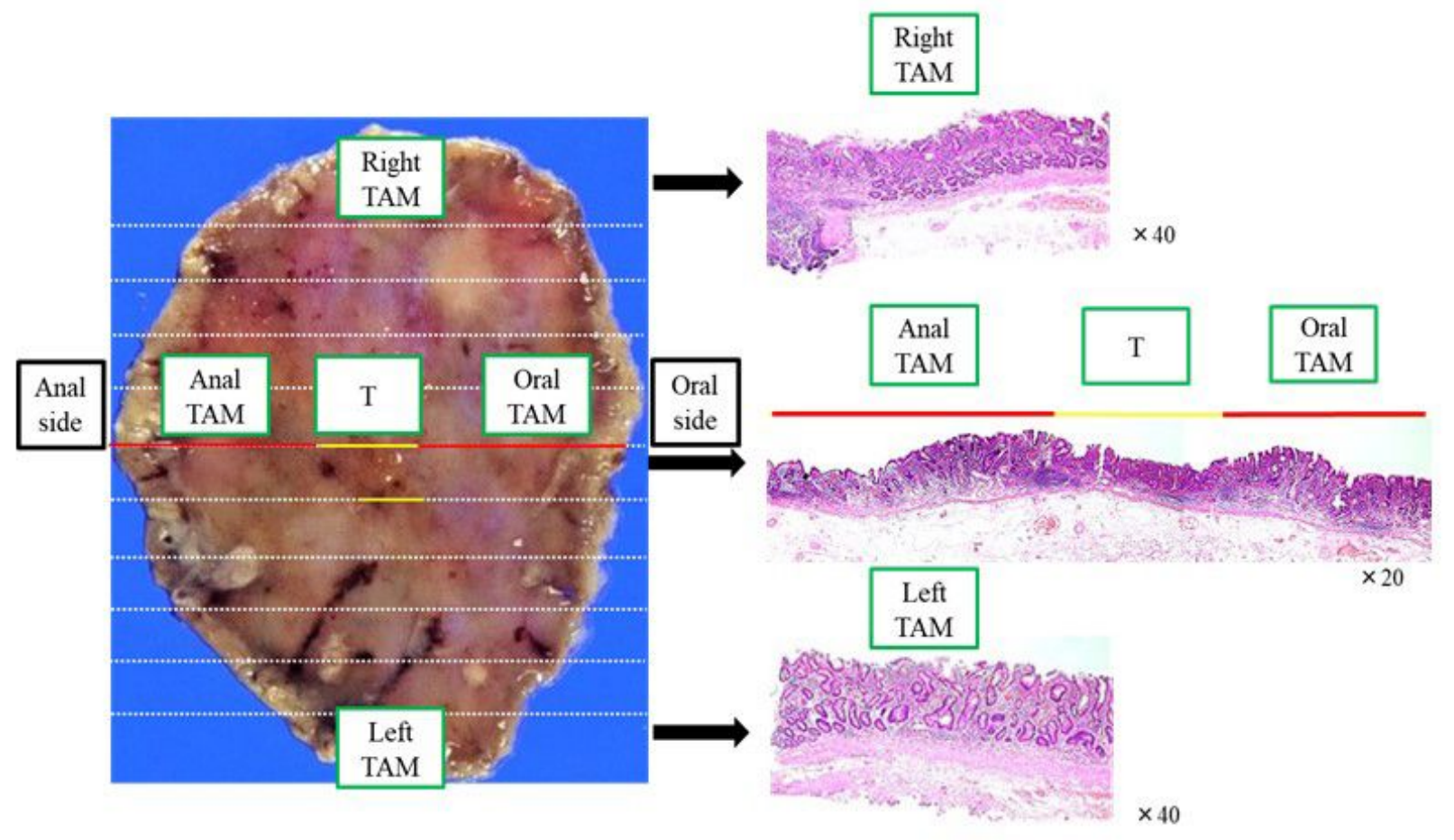

Figure 6

Definition of sample locations for DNA extraction Definition of sample locations for DNA extraction (left panel) and genomic DNA extracted from the T and the separate TAM (4-points: oral TAM, anal TAM, right TAM, and left TAM) tissues. Corresponding pathological findings are shown in the right panels. T, tumor; TAM, tumor-adjacent noncancerous mucosa 